\title{
THE PROTESTANT FACTOR OF DEVELOPMENT OF THE LOWER VOLGAAND THE DON: IN THE WRITINGS OF HISTORIANS OF THE VOLGOGRAD STATE UNIVERSITY
}

\author{
Vasiliy V. Tarakanov \\ Volgograd State University, Volgograd, Russian Federation \\ Olga Yu. Redkina \\ Volgograd State University, Volgograd, Russian Federation \\ Tatyana P. Nazarova \\ Volgograd State Agrarian University, Volgograd, Russian Federation
}

\begin{abstract}
The article analyzes the theses presented by the historians of the Volgograd State University and devoted to studying the influence of the Protestant factor on the socio-economic, political and cultural development of the Lower Volga region and the Don region. The authors point to a high contribution of the researchers to the study of such aspects as socio-economic and cultural development of the Protestant communities, the emigration of Germans and Mennonites to America and Canada, the features of cooperative construction and the implementation of agrarian reform of P.A. Stolypin in the colonies, the assistance by foreign Mennonite organizations during the famine and NEP, as well as the specifics of development of Russian Protestantism in the Volga region.

T.P. Nazarova determines the contribution of the VolSU researchers to the study of pre-revolutionary stage of Protestantism development in Russia. V.V. Tarakanov analyzes the works that characterize the activities of Protestant cooperation. O.Yu. Redkina discloses the problem of state-confessional relations in the USSR in dissertational studies of the VolSU historians, substantiates the further directions of research in the historiography of Protestantism in Russia.

Key words: Protestantism, Reformation, German colonies, the Lower Volga, the Don, historians of the VolSU.

Citation. Tarakanov V.V., Redkina O.Yu., Nazarova T.P. The Protestant Factor of Development of the Lower Volga and the Don: in the Writings of Historians of the Volgograd State University. Vestnik Volgogradskogo ¿े gosudarstvennogo universiteta. Seriya 4, Istoriya. Regionovedenie. Mezhdunarodnye otnosheniya [Science Journal ․ of Volgograd State University. History. Area Studies. International Relations], 2017, vol. 22, no. 6, pp. 172-177. (in Russian). DOI: https://doi.org/10.15688/jvolsu4.2017.6.17
\end{abstract}

\section{ПРОТЕСТАНТСКИЙ ФАКТОР В РАЗВИТИИ НИЖНЕЙ ВОЛГИ И ДОНА: В ТРУДАХ ИСТОРИКОВ ВОЛГОГРАДСКОГО ГОСУДАРСТВЕННОГО УНИВЕРСИТЕТА}

\author{
Василий Валерьевич Тараканов \\ Волгоградский государственный университет, г. Волгоград, Российская Федерация \\ Ольга Юрьевна Редькина \\ Волгоградский государственный университет, г. Волгоград, Российская Федерация
}




\section{Татьяна Павловна Назарова}

Волгоградский государственный аграрный университет, г. Волгоград, Российская Федерация

Аннотация. В статье анализируются диссертации, защищенные историками ВолГУ и посвященные изучению влияния протестантского фактора на социально-экономическое, политическое и культурное развитие региона Нижней Волги и Дона. Отмечается высокий вклад исследователей университета в изучение таких аспектов, как социально-экономическое и культурное развитие протестантских общин, проблемы эмиграции немцев и меннонитов в Америку и Канаду, особенности кооперативного строительства и проведения аграрной реформы П.А. Столыпина в колониях, помощь зарубежных меннонитских организаций во время голода и нэпа, а также специфика развития русского протестантизма в Поволжье.

Т.П. Назарова определила вклад ученых ВолГУ в изучение дореволюционного этапа развития протестантизма в России. В.В. Таракановым был проведен анализ работ, характеризовавших деятельность протестантской кооперации. О.Ю. Редькина раскрыла проблему государственно-конфессиональных отношений в СССР в диссертационных исследованиях историков ВолГУ, обосновала дальнейшие направления исследований в историографии протестантизма в России.

Ключевые слова: протестантизм, Реформация, немецкие колонии, Нижняя Волга, Дон, историки ВолГУ.

Цитирование. Тараканов В. В., Редькина О. Ю.,Назарова Т. П. Протестантский фактор в развитии Нижней Волги и Дона: в трудах историков Волгоградского государственного университета // Вестник Волгоградского государственного университета. Серия 4, История. Регионоведение. Международные отношения. 2017. - T. 22, № 6. - C. 172-177. - DOI: https://doi.org/10.15688/jvolsu4.2017.6.17

В 2017 г. во всем научном и религиозном мире широко отмечается 500-летие Реформации и возникновения протестантизма. В России этот юбилей остается в тени другой годовщины - 100-летия революции, но в научном сообществе обратили внимание на тесную связь и важные параллели между российской революцией и западной Реформацией, занялись поиском общих методологических подходов к осмыслению этих событий, которые существенно повлияли на мировую историю, внесли кардинальные изменения во все сферы жизни и, в то же время, привели к расколу и войнам. Россию можно назвать одним из очагов развития Реформации, так как протестанты проникли в страну достаточно рано и стали одной из ведущих преобразовательных сил общества, катализатором модернизационных процессов, носителями европейских ценностей и демократических традиций.

Важность протестантского фактора в развитии российского общества осознается и на региональном уровне. В стенах Волгоградского государственного университета сложилась устойчивая научная традиция по изучению влияния протестантского фактора на социально-экономическое, политическое и культурное развитие региона Нижней Волги и Дона, о чем свидетельствует анализ защищенных диссертаций за последние двадцать лет. В центре внимания ученых стояли прежде всего вопросы социально-экономического развития протестантских общин, эмиграционные процессы, проблемы взаимоотношения протестантов с властью на разных этапах.

Огромный вклад в изучение данной проблемы внесла профессор Н.Э. Вашкау. Занимаясь различными аспектами истории российских немцев, Н.Э. Вашкау часто затрагивала вопросы, связанные с жизнью лютеранских и меннонитских колоний Поволжья. Несколько выпусков сборников трудов основанного ею Волгоградского центра германских исторических исследований было посвящено колонии Сарепта. В докторской диссертации Н.Э. Вашкау проанализировала систему образования как неотъемлемую часть духовной жизни немцев Поволжья на протяжении длительного периода - от основания первых колоний до депортации 1941 года. Н.Э. Вашкау рассмотрела тесную взаимосвязь школы и церкви в немецких колониях и доказала, что именно они являлись основными институтами по сохранению немецкой культуры и восприятию культуры окружающих народов. В исследовании присутствует много материалов о влиянии католической и лютеранской церкви на становлениеи эволюцию немецкой национальной школы в Поволжье [2].

Е.В. Ананян провела комплексное исследование первой волны эмиграции поволжских колонистов в Америку (в 70-е гг. XIX в.). Зна- 
чительную долю выехавших составили именно протестантские группы (особенно меннониты), которые боялись потерять свой особый статус в пореформенный период из-за проходившего процесса унификации групп сельского населения. Диссертационная работа Е.В. Ананян позволила впервые воссоздать картину зарождения и развития внутренней миграции в немецком Поволжье, а эмиграцию представить в русле миграционных процессов, начало которых историк отнесла к 30-40-м гг. XIX века. В работе представлен новый взгляд на причины эмиграционных настроений среди колонистов, акцент перенесен с политических факторов на экономические. На широком историческом материале было доказано, что сокращение земельных наделов и обезземеливание в колониях Поволжья, начавшись в 30-40-х гг. XIX в., продолжились и усилились в пореформенный период, что и стало основным толчком к эмиграции, а отмена привилегий лишь усилила эти настроения. Особый интерес в исследовании представляет и изучение дальнейшей судьбы немцев и меннонитов Поволжья в Америке [1].

Проблемы социально-экономического развития немецких колоний в Поволжье на следующем важном историческом рубеже - в период аграрной реформы П.А. Столыпина - продолжили изучать Е.К. Розина и Е.Л. Фурман. Изучение опыта проведения аграрных преобразований в немецких колониях Саратовской губернии позволило Е.К. Розиной сделать вывод о более широком охвате реформой немецкого населения по сравнению с русскими крестьянами и в целом поддержке ее со стороны колонистов. Помимо этого, были выделены и другие особенности проведения реформы: ее пик в немецких поселениях пришелся на 1910-1914 гг., когда в русских деревнях реформа затормозилась; также немецкие крестьяне, в отличие от русских, выходили на отруба и хутора целыми селениями, а не отдельными домохозяйствами. При этом автор учла специфику ее проведения в немецких и меннонитских поселениях с учетом разных форм землепользования - общинного и хуторского [6]. В диссертации Е.Л. Фурман было проанализировано развитие кооперативного движения в немецких колониях Поволжья (от аграрной реформы П.А. Столыпина до коллективиза- ции), проведен сравнительный анализ дореволюционного и советского этапа в становлении кооперации, также затронута деятельность меннонитских кооперативов Саратовского и Самарского Поволжья как наиболее успешных организаций периода нэпа [7].

Первая мировая война внесла свои коррективы в развитие протестантизма в России, так как развернувшаяся в стране борьба с «немецким засильем» затронула и религиозную сферу. Борцы с религиозным инакомыслием увидели в войне лишний повод для выступления против духовных движений вне официального православия. В диссертации Н.В. Морозовой была проанализирована роль центральной периодической печати в формировании и развитии общественного мнения по «немецкому вопросу» в годы Первой мировой войны. Было проведено фронтальное исследование материалов более тридцати центральных изданий разной жанровой и политической направленности. В работе нашли отражение и региональные материалы о влиянии антинемецких настроений и «ликвидационных законов» на положение немцев Поволжья. Автор обратила внимание на значительный интерес ряда изданий к вопросу о роли протестантизма в «преображении» Германии из «цивилизованной страны» в «варварскую». Н.В. Морозова наглядно показала, как ряд газет пытались внедрять в общественное сознание идею о том, что русские протестанты - это тайные шпионы и пособники Вильгельма II, так как являются носителями «немецкой веры» [3].

О.Ю. Редькина в докторской диссертации проанализировала феномен «сельскохозяйственных религиозных трудовых коллективов» (далее - СХРТК) в контексте аграрной политики советской власти в 1917-м - 1930-е годы. Впервые были определены качественные характеристики данного явления; охарактеризована работа Наркомзема по поддержке СХРТК; уточнена численность и вероисповедная принадлежность СХРТК в целом и по отдельным регионам европейской части РСФСР, в том числе по Нижневолжской зоне; было раскрыто влияние на развитие СХРТК внешних и внутренних факторов. В данном контексте была подробно проанализирована хозяйственно-производственная деятельность протестан- 
тских трудовых коллективов, доказан их высокий вклад в развитие отраслей аграрного производства и сельскохозяйственной кооперации РСФСР. Особо следует отметить проведенное О.Ю. Редькиной исследование деятельности самого крупного и наиболее организованного СХРТК - Всероссийского меннонитского сельскохозяйственного общества и его региональных отделений [5].

В диссертации Т.П. Назаровой было продолжено рассмотрение проблематики, связанной с эмиграцией и кооперативным строительством в меннонитских колониях в период нэпа, хотя само исследование было посвящено более узкой теме - помощи меннонитских благотворительных организаций США, Канады, Голландии, Германии единоверцам в Советском государстве в 1920-е годы. Исследуемые события завершают важный этап истории одной из наиболее успешных протестантских групп в России - меннонитских общин, делая ее финал (эмиграцию, распад менонитского сообщества) более понятным. В исследовании изучена роль зарубежной помощи в борьбе с голодом и в восстановлении хозяйства во всех местах компактного проживания меннонитов на территории СССР, включая Автономную область немцев Поволжья и Дон; на широком статистическом материале раскрыта региональная специфика социально-экономического развития поселений в данный период. Так же, как и в работе Е.В. Ананян, вновь отмечалась значительная роль зарубежных центров в эмиграции меннонитов в Америку и Канаду, что ставило их в более благоприятные условия по сравнению с другими эмигрантскими потоками [4].

Относительно слабо исследованным этапом в судьбе протестантских групп нашего региона остается период Второй мировой войны и послевоенное развитие. Такая тенденция коррелирует с историографией российских немцев, для которой также характерен сильный перекос в сторону довоенной истории, что связано с источниковой базой и депортацией немцев Поволжья в другие регионы. Поэтому особую актуальность и новизну несут работы по данному периоду.

Исследование Г.И. Хвостовой раскрывает принципы, формы и механизмы взаимодействия между органами государственной вла- сти и религиозными организациями в Волгоградской области в период «позднего» СССР. Особое внимание в диссертации было уделено взаимоотношениям протестантских объединений и органов региональной власти. Именно протестантские общины в подавляющем большинстве находились в непримиримой оппозиции к религиозной политике Советского государства, и в исследуемый период в Волгоградской области, по наблюдениям Г.И. Хвостовой, шел процесс расширения сети нелегальных и бесконтрольных религиозных организаций, в частности объединений пятидесятников, свидетелей Иеговы, баптистов-«инициативников», лютеран [8].

Таким образом, историки Волгоградского государственного университета изучили специфику социально-экономического, политического и культурного развития протестантских общин на российской почве, существенно углубили представления о вкладе протестантизма в модернизационные процессы в таком поликонфессиональном и мультикультурном регионе, как Нижняя Волга и Дон. Анализ диссертаций позволяет также наметить и перспективы дальнейших исследований: в частности, не хватает статистических данных (в динамике) по численности протестантских поселений на территории края, их пространственной локализации на карте; есть необходимость в обобщающем исследовании по всем протестантским группам на территории региона.

\section{СПИСОК ЛИТЕРАТУРЫ}

1. Ананян, Е. В. Эмиграция немцев Поволжья в Америку в 70-е годы XIX в.: предпосылки, причины и результаты : автореф.дис. ... канд. ист. наук : 07.00.02 / Ананян Елена Виллиевна. - Волгоград, 2004. $-26 \mathrm{c}$.

2. Вашкау, Н. Э. Духовная культура немцев Поволжья: проблемы школы и образования, 17641941 гг.: автореф. дис. ... д-ра ист. наук : 07.00 .02 / Вашкау Нина Эмильевна. - Саратов, 1998. - 38 с.

3. Морозова, Н. В. Немецкий вопрос и центральная периодическая печать России : июль 1914февраль 1917 гг. : автореф. дис. ... канд. ист. наук : 07.00.02 / Морозова Наталия Владимировна. - Волгоград, 2010.- $23 \mathrm{c}$.

4. Назарова, Т. П. Благотворительная деятельность зарубежных меннонитских организаций в советском государстве : 1920-1930 гг. : автореф. дис. ... 
канд. ист.наук : 07.00.02 / Назарова Татьяна Павловна. - Волгоград, 2010. - 24 с.

5. Редькина, О. Ю.Сельскохозяйственные религиозные трудовые коллективы в 1917 - 1930-е гг. : на материалах европейской части РСФСР : автореф. дис. ... д-ра ист. наук : 07.00.02 / Редькина Ольга Юрьевна. - Волгоград, 2004. -45 с.

6. Розина, Е. К. Столыпинская аграрная реформа в немецких колониях Саратовской губернии : автореф. дис. ... канд. ист. наук : 07.00.02 / Розина Елена Кимовна. - Волгоград, 2005. - 25 с.

7. Фурман, Е. Л. Кооперативное движение в немецких колониях Поволжья : 1906 - начало 1930-х гг. : автореф. дис. ... канд. ист. наук : 07.00.02 / Фурман Екатерина Львовна.- Волгоград, 2008. - 29 с.

8. Хвостова, Г. И. Государственно-конфессиональные отношения в Волгоградской области в 1975 1990 гг. : автореф. дис. ... канд. ист. наук : 07.00.02 / Хвостова Галина Ивановна. - Волгоград, 2010. - 24 с.

\section{REFERENCES}

1. Ananyan E.V. Emigratsiya nemtsev Povolzhya v Ameriku v 70-e gody XIX v.: predposylki, prichiny i rezultaty: avtoref. dis. ... kand. ist. nauk [The Emigration of the Volga Germans to America in the 1870s: Preconditions, Causes and Results. Cand. hist. sci. abs. diss.]. Volgograd, 2004. 26 p.

2. Vashkau N.E. Dukhovnaya kultura nemtsev Povolzhya: problemy shkoly i obrazovaniya, 17641941 gg.: avtoref. dis. ... d-ra ist. nauk [The Spiritual Culture of the Volga Germans: Problems of the School and Education, 1764-1941. Dr. hist. sci. abs. diss.]. Saratov, 1998. 38 p.
3. Morozova N.V. Nemetskiy vopros $i$ tsentralnaya periodicheskaya pechat Rossii: iyul 1914 - fevral 1917 gg.: avtoref. dis. ... kand. ist. nauk [The German Issue and the Central Periodicals of Russia: July 1914 - February 1917. Cand. hist. sci. abs. diss.]. Volgograd, 2010. 23 p.

4. Nazarova T.P. Blagotvoritelnaya deyatelnost zarubezhnykh mennonitskikh organizatsiy $v$ sovetskom gosudarstve: 1920-1930 gg.: avtoref. dis. ... kand. ist. nauk [The Charity Activity of Foreign Mennonite Organizations in the Soviet Union: the 1920s - 1930s. Cand. hist. sci. abs. diss.]. Volgograd, 2010. 24 p.

5. Redkina O.Yu. Selskokhozyaystvennye religioznye trudovye kollektivy v 1917-1930-e gg.: na materialakh evropeyskoy chasti RSFSR: avtoref. dis. ... d-ra ist. nauk [The Religious Agricultural Labour Groups in 1917-1930s: Based on the Materials of the European Part of the RSFSR. Dr. hist. sci. abs. diss]. Volgograd, 2004. 45 p.

6. Rozina E.K. Stolypinskaya agrarnaya reforma $v$ nemetskikh koloniyakh Saratovskoy gubernii: avtoref. dis. ... kand. ist. nauk [The Stolypin Agrarian Reform in the German Colonies of the Saratov Province. Cand. hist. sci. abs. diss.]. Volgograd, 2005. 25 p.

7. Furman E.L. Kooperativnoe dvizhenie v nemetskikh koloniyakh Povolzhya: 1906 - nachalo 1930-kh gg.: avtoref. dis. ... kand. ist. nauk [The Cooperative Movement in the German Colonies of the Volga Region : 1906 - Early 1930s. Cand. hist. sci. abs. diss.]. Volgograd, 2008. 29 p.

8. Khvostova G.I. Gosudarstvennokonfessionalnye otnosheniya $v$ Volgogradskoy oblasti v 1975-1990 gg.: avtoref. dis. ... kand. ist. nauk [ChurchState Relations in the Volgograd Region in 1975-1990. Cand. hist. sci. abs. diss.]. Volgograd, 2010. 24 p.

\section{Information about the Authors}

Vasiliy V. Tarakanov, Doctor of Sciences (Economics), Professor, Rector of Volgograd State University, Prosp. Universitetsky, 100, 400062 Volgograd, Russian Federation, rector@volsu.ru, https:// orcid.org/0000-0001-6971-0172

Olga Yu. Redkina, Doctor of Sciences (History), Professor, Department of International Relations, Political Science and Area Studies, Volgograd State University, Prosp. Universitetsky, 100, 400062 Volgograd, Russian Federation, redkina@volsu.ru, https://orcid.org/0000-0002-8978-9575

Tatyana P. Nazarova, Candidate of Sciences (History), Associate Professor, Department of Agrotourism and Local Regional Study, Volgograd State Agrarian University, Prosp. Universitetsky, 26, 400002 Volgograd, Russian Federation, hist_tatyana@mail.ru, https://orcid.org/0000-0003-1701-9237

\section{Информация об авторах}

Василий Валерьевич Тараканов, доктор экономических наук, профессор, ректор Волгоградского государственного университета, просп. Университетский, 100, 400062 г. Волгоград, Российская Федерация, rector@volsu.ru, https://orcid.org/0000-0001-6971-0172 
В.В. Тараканов, О.Ю. Редькина, Т.П. Назарова. Протестантский фактор в развитии Нижней Волги и Дона

Ольга Юрьевна Редькина, доктор исторических наук, профессор кафедры международных отношений, политологии и регионоведения, Волгоградский государственный университет, просп. Университетский, 100, 400062 г. Волгоград, Российская Федерация, redkina@volsu.ru, https:// orcid.org/0000-0002-8978-9575

Татьяна Павловна Назарова, кандидат исторических наук, доцент кафедры агротуризма и регионального краеведения, Волгоградский государственный аграрный университет, просп. Университетский, 26, 400002 г. Волгоград, Российская Федерация, hist_tatyana@mail.ru, https://orcid.org/ 0000-0003-1701-9237 